\title{
Clinical and EEG Features, Treatment, and Outcome of Hot Water Epilepsy in Pediatric Patients
}

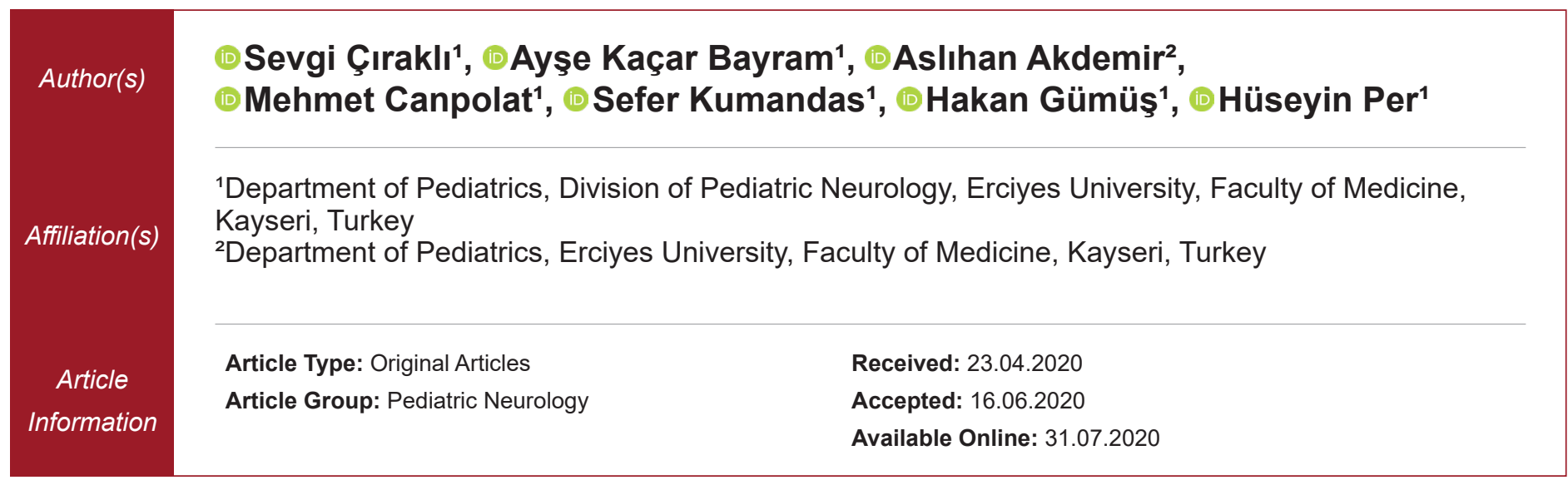

\section{Abstract}

Hot water epilepsy is a type of reflex epilepsy which generally occurs with pouring water on the body during bath. The aim of this study is to evaluate the clinical and electrophysiological features, treatment, and outcome of the pediatric patients with diagnosis of hot water epilepsy. Patients were followed and treated at Erciyes University, between January 2010 and January 2016. There were 15 patients total, included $9(60 \%)$ boys and $6(40 \%)$ girls. The average age at diagnosis was 30 months (range: 13-60 months). The follow-up period was 16 months (range: $12-48$ months). Seven patients $(46.6 \%)$ had focal seizures with impaired consciousness, four $(26.7 \%)$ had focal seizure and four $(26.7 \%)$ had focal starting and generalized tonic-clonic continuing seizures. Seven patients $(46.6 \%)$ had abnormal interictal EEG findings, ranged from unilateral slowing of the background activity to bilateral sharp wave. Intermittent clobazam treatment $(0.8-1.2 \mathrm{mg} / \mathrm{kg})$ was given to 13 patients $(86.7 \%)$. Other epileptic treatments were used in $5(33.3 \%)$ patients. Three patients $(20.0 \%)$ developed nonreflex seizures during followup period. Intermittent clobazam prophylaxis prior to hot water bath, as well as changing bathing habits can be effective in pediatric patients with hot water epilepsy.

Keywords: Hot water epilepsy, electroencephalography, clobazam, reflex epilepsy 


\section{Introduction}

Reflex epilepsy is an epileptic event triggered exclusively by an external stimulus such as light, sound, eating, reading, and listening to music. ${ }^{1,2}$ The rate of reflex epilepsies among all epileptic seizures is about $5-6 \%{ }^{3}$ Hot water epilepsy (HWE) is a form of reflex epilepsy, requires a specific thermal cutaneous stimulus, triggered by bath with hot water, poured over the head. HWE described as water temperature higher then 37 , is this necessary creteria. ${ }^{4}$ It is more frequent in Southern India and Turkey, but rarely seen in European countries. ${ }^{1,2,5,6}$ HWE is more frequent in childhood and male/female ratio is 2.6-3.6/1.0. .,6 Seizures are generally focal with impaired consciousness type; however, they can also be focal starting and generalized tonicclonic continuing type. ${ }^{6,7}$

In this study, we evaluated the clinical and EEG characteristics, treatments, and outcomes of children with HWE who were followed in our pediatric neurology clinic.

\section{Materials and Methods}

Informed consent information was obtained from all patients in the study and the research protocols were approved by the Ethics Committee at Erciyes University (date: 07.04.2017, number: 2017/210).

\section{Subjects}

The patients were examined in terms of age, gender, bathing habits, detailed physical examination findings, type of seizure, EEG findings, cranial magnetic resonance findings and the treatment given and its prognosis.

15 cases followed and treated with diagnosis of hot water epilepsy at Erciyes University, Faculty of Medicine, Pediatric Neurology Department between January 2010 and January 2016 were assessed retrospectively. The study protocol was approved by Local Ethics committee of Erciyes University. Informed consent was taken before the study from the parents or legal guardians of the all patients. All patients underwent detailed neurological examination, routine laboratory examinations, imaging techniques, detailed anamnesis were taken from the patients and their EEG records were taken. The patients were assessed in terms of age, gender, bathing habits and frequencies, type of seizure, response to treatment, period of follow-up and complications. The cases assessed as hot water epilepsy were those whose bathing water temperature was over $37^{\circ} \mathrm{C}$.

\section{Statistical Analysis}

The data uploaded to SPSS (SPSS Inc., Chicago, IL, USA) system, Shapiro-Wilk test was used to find out if the data were normally distributed. The data which were normally distributed were expressed as average \pm standard deviation, while the data which were not normally distributed were expressed as median (min-max).

\section{Results}

Nine of the cases (60\%) were male, while 6 were female $(40 \%)$ and the average age was 30 months (distributed between 13 to 60 months). 14 (93.3\%) cases were bathed in the bathtub by their families, while $1(6.6 \%)$ case bathed alone while standing. $2(13.3 \%)$ cases had a history of previous febrile convulsion. None of the cases had a history of hot water epilepsy in the family. The siblings of 2 (13.3\%) cases had idiopathic epilepsy.

The follow-up period was 16 months (distributed between 12 to 48 months). It was learned that the cases bathed with water more than 37 degrees hot. 12 (80\%) of the cases developed reflex epilepsy when hot water was poured down through the head, while $2(13.3 \%)$ developed reflex epilepsy when hot water touched the neck and the face and 1 case $(6.6 \%)$ developed reflex epilepsy when hot water touched anywhere in his body.

Seizure types were focal in 4 $(26.6 \%)$ cases, focal with impaired consciousness in 7 (46.6\%) cases and focal starting and generalized tonic-clonic continuing in 4 (26.6\%) cases. Seizures disappeared completely in 2 (13.3\%) cases when they changed bathing habits. In 8 (53.3\%) cases, seizures were prevented with clobazam treatment given between $45 \mathrm{~min}$ to $60 \mathrm{~min}$ before bath. Carbamazepine was started to $1(6.6 \%)$ case and topiramate was started to $1(6.6 \%)$ case that could not provide clobazam. Of the 3 $(20.0 \%)$ cases that developed non-reflex epilepsy during the treatment, $1(6.6 \%)$ case benefited from clobazam + carbamazepine treatment, $2(13.3 \%)$ cases benefited from phenobarbital + clobazam treatment (Table 1). The time between reflex and non-reflex seizures was 8.4 months (ranged: 7-12 months). All the medications except clobazam were taken continually like in epilepsy protocol, while clobazam was applied only 45 min-60 min before bath. No side effects of medication were seen in the patients.

In terms of EEG findings, during the interictal period, 8 patients $(53.3 \%)$ had completely normal EEG findings, 2 patients $(13.3 \%)$ had slowing at the base rhythm at unilateral temporoparietal areas, 1 patient $(6.6 \%)$ had slowing at the base rhythm at bilateral temporoparietal areas, 2 patients $(13.3 \%)$ had sharp wave activity at bilateral frontotemporal area while 2 patients (13.3\%) had sharp wave activity unilateral at frontotemporal area. There was no obvious pathology in brain MRG's

\section{Discussion}

Hot water epilepsy was first defined by Allen in New Zealand in 1945. Studies are generally in the form of case reports and there are also a few large cohort studies in literature. ${ }^{7-10}$ Our cohort has 15 pediatric cases from a reference center in Kayseri, an urban area in central 


\begin{tabular}{lcccccc}
\hline Patients & Age (months) & Gender & Bathing habits & Seizure type & Treatment & Follow-up (months) \\
\hline 1 & 18 & F & Bathtub & Generalized & Clobazam & 12 \\
2 & 36 & M & Bathtub & Complex partial & Clobazam & 36 \\
3 & 13 & F & Bathtub & Generalized & Phenobarbital+clobazam & 48 \\
4 & 24 & F & Bathtub & Simple partial & - & 12 \\
5 & 60 & M & Bathtub & Complex partial & Clobazam Carbamezapine & 36 \\
6 & 18 & M & Bathtub & Generalized & Clobazam & 48 \\
7 & 48 & M & Bathtub & Simple partial & Clobazam & 36 \\
8 & 60 & M & Bathtub & Simple partial & - & 24 \\
9 & 36 & M & Bathtub & Complex partial & Clobazam & 12 \\
10 & 60 & F & Bathtub & Complex partial & Topiramate & 18 \\
11 & 36 & M & Shower & Complex partial & Clobazam & 36 \\
12 & 24 & F & Bathtub & Simple partial & Carbamezapine+clobazam & 24 \\
13 & 18 & M & Bathtub & Generalized & Phenobarbital + clobazam & 20 \\
14 & 26 & F & Bathtub & Complex partial & Clobazam & 14 \\
15 & 45 & M & Bathtub & Complex partial & Clobazam & 17 \\
\hline
\end{tabular}

Anatolia, and it is one of the largest cohort studies from Turkey.

The pathophysiology of the disease is not known completely; however, seizures are generally triggered by pouring down water from the head. The onset age of the disease, which is in the first decade, varies in literature and it is 2-3 times more frequent in men.,4,11 The disease has been reported in South India frequently and it makes up $3.6-3.9 \%$ of all epilepsy cases. This rate is $0.6 \%$ in our country. ${ }^{3,10,12}$ This brings to mind that bathing habits are different in these areas. People living in these areas pour $40-50^{\circ} \mathrm{C}$ water down their heads successively in a fast way during bathing. ${ }^{12,13}$ In our country, it is common in specific areas to pour down water with a cup by using tub, basin and/or boiler. 14 (93.3\%) cases have habit of bathing in the tub with their families, while $1(6.6 \%)$ case has habit of bathing alone while standing. The onset age of seizures was 2.5 years of age on average and it was found to be lower when compared with literature.

While febrile convulsion and head trauma can be seen in the backgrounds of hot water epilepsy cases, intracranial malformation is very rare. ${ }^{4,14} 1(6.6 \%)$ of our cases had history of head trauma. The rate of epilepsy in family has been reported as $18-22 \%$ and this rate supports the presence of genetic predisposition. ${ }^{1,9,15}$ None of our cases' families had a history of hot water epilepsy, the siblings of $2(13.3 \%)$ cases had idiopathic epilepsy. 2 $(13.3 \%)$ of the cases have history of febrile convulsion. In addition, an autosomal recessive genetic predisposition of the disease has also been reported. ${ }^{10,11}$

Seizures are frequently focal with impaired consciousness. ${ }^{12}$ In our study, the most frequent type was focal seizure with impaired consciousness with 7 cases $(46.6 \%)$, which was in line with literature.

As for treatment, the patient and the family should first be informed about staying away from hot water which causes seizure, using warm water while bathing and pouring water slowly instead of pouring water on the head and body fast. Seizures of some patients have been prevented even with this method only. 2 (13.3\%) of our cases' seizures discontinued by changing bathing habits alone. Different antiepileptic drugs are used in the medical treatment of the disease. Clobazam is a novel option for preventing and seems to be an appropriate choice. ${ }^{16-18}$

Most reports of HWE are from India and Turkey, suggesting a genetic predisposition. A genetically aberrant thermoregulatory system or an anatomical abnormality of the temporo-insular and parietal networks has been suggested as a possible mechanism for epiloptogenesis. ${ }^{19,20}$ HWE is caused by an X-linked gene-such as SYN1 -in a significant proportion of individuals. ${ }^{21}$

Conclusions: Intermittent clobazam prophylaxis prior to hot water bath, as well as changing bathing habits can be effective in pediatric patients with hot water epilepsy. Other anti-epileptics should be used in patients who do not benefit from changing bathing habits, in cases who cannot provide clobazam or who do not benefit from clobazam and in cases who have non-reflex epileptic seizures.

Acknowledgement: We would like to thank all patients and families for their participation in this study.

Ethics Committee Approval: This study was approved by the Local Ethics Committee of Erciyes University (date: 07.04.2017, number: 2017/210).

Informed Consent: Written informed consent was obtained from patients who participated in this study.

Peer-review: Externally peer-reviewed.

Author Contributions: HP conceived the study. HP, SÇ, $A K B, A A, M C, H G$ and SK were involved in patient care, including the process of procedure and routine clinical follow-up. HP, SÇ, AA and AKB performed the literature review and wrote the manuscript. SÇ, AKB also made statistical analysis. HP, HG and SK also made helpful suggestions to improve the manuscript. 
Conflict of Interest: The authors have no conflict of interest to declare.

Financial Disclosure: The authors declared that this study has received no financial support.

\section{References}

1. Meghana A, Sinha S, Sathyaprabha TN, et al. Hot water epilepsy clinical profile and treatment-a prospektive study. Epilepsy Res. 2012; 102: 160-166. [CrossRef]

2. Eroğlu E, Gökçil Z, Özdağ MF, et al. Hot water epilepsy. Epilepsi 1998; 4: 90-92. [CrossRef]

3. Incecik F, Herguner MO, Elkay M, et al. Hot water epilepsy -a report of three cases. Indian Pediatr. 2004; 41: 731-733. [CrossRef]

4. Satishchandra P. Hot water epilepsy. Epilepsia. 2003; 44: 29-32. [CrossRef]

5. Grosso S, Farnetani MA, Francione S, et al. Hot water epilepsy and focal malformation of the parietal cortex development. Brain Dev. 2004; 26: 490-493. [CrossRef]

6. Szymonowicz W, Meloff KL. Hot water epilepsy. Can J Neurol Sci. 1978; 5: 247-251. [CrossRef]

7. Yalçın AD, Toydemir HE, Forta H. Hot water epilepsy: clinical and electroencephalographic features of 25 cases. Epilepsy Behav. 2006; 9: 89-94. [CrossRef]

8. Allen IM. Observation on cases of reflex epilepsy. $N Z$ Med J. 1945; 44: 135-142. [CrossRef]

9. Fukuda M, Morimoto T, Nagao H, et al. Clinical study of epilepsy with severe febrile seizures and seizures induced by hot water bath. Brain Dev. 1997; 19: 212-216. [CrossRef]

10. Bebek N, Gürses C, Gökyiğit A, et al. Hot water epilepsy: clinical and electrophysiologic findings based on 21 cases. Epilepsia.
2001; 42: 1180-1184. [CrossRef]

11. Auvin S, Lamblin MD, Pandit F, et al. Hot water epilepsy occurring at temperature below the core temperature. Brain Dev. 2006; 28: 265-268. [CrossRef]

12. Ritaccio AL. Reflex seizures. Neurol Clin. 1994; 12: 57-83. [CrossRef]

13. Roos RA, van Dijk JG. Reflex-epilepsy induced by immersion in hot water. Case report and review of literature. Eur Neurol. 1988; 28: 6-10. [CrossRef]

14. Tajima Y, Minami N, Sudo K, et al. Hot water epilepsy with pineal cyst and cavum septum pellucidi. Jpn J Psychiatry Neurol. 1993; 47: 111-114. [CrossRef]

15. Grunanj G, Satishchandra P. Correlates of hot water epilepsy in rural Saouth India: a descriptive study. Neuroepidemiogy. 1992; 11: 173-179. [CrossRef]

16. Ekici A, Ozdemir O, Yimenicioglu S, et al. Hot water epilepsy successfully treated with daily clobazam. Pediatr Emerg Care. 2017; 33: e98-e99. [CrossRef]

17. Dhanaraj M, Jayavelu A. Prophylactic use of clobazam in hot water epilepsy. J Assoc Physicians India. 2003; 51: 43-44. [CrossRef]

18. Satishchandra $P$, Dilipkumar $S$, Subbakrishna DK, et al. Intermittent clobazam prophylaxis in hot water epilepsy is safe and effective: a prospective study. Epilepsy Res. 2014; 108: 1238-1242. [CrossRef]

19. Mosquera-Gorostidi A, Azcona-Ganuza G, Yoldi-Petri ME, et al. Ictal video-electroencephalography findings in bathing seizures: two new cases and review of the literature. Pediatr Neurol. 2019; 99: 76-81.[CrossRef]

20. Panda PK, Sharawat IK. Bathing and hot water epilepsy. Pediatr Neurol. 2020; 104: 72. [CrossRef]

21. Peron A, Baratang NV, Canevini MP, et al. Hot water epilepsy and SYN1 variants. Epilepsia. 2018; 59: 2162-2163. [CrossRef] 